\title{
Familial isolated hypoparathyroidism due to agenesis of parathyroid gland
}

INSERM

\section{Source}

INSERM. (1999). Orphanet: an online rare disease and orphan drug data base. Familial isolated hypoparathyroidism due to agenesis of parathyroid gland. ORPHA:2239

X-linked recessive hypoparathyroidism (XLHPT) is a very rare cause of hypoparathyroidism. It has been reported in two multigeneration families from Missouri. Affected males suffer from true neonatal idiopathic hypoparathyroidism leading to severe hypocalcemia with undetectable parathyroid hormone levels and epilepsy. They are also sterile. Carrier females are normocalcemic and asymptomatic. XLHPT is caused by congenital parathyroid gland agenesis. The XLHPT locus has been mapped to chromosome Xq26-q27, in a 1.5 Mb interval flanked by markers F9 and DXS984. Neonatal onset and parathyroid agenesis found at autopsy in one of the patients suggest that the gene involved in XLHPT plays a role in parathyroid gland development. 